\title{
REVIEWS
}

\section{Oral Microbiology: Past, Present and Future}

\author{
Xue-song He, Wen-yuan Shi*
}

School of Dentistry, the University of California, Los Angeles, USA

\begin{abstract}
Xue-song He, Wen-yuan Shi. Oral Microbiology: Past, Present and Future. International Journal of Oral Science, 1(2): 47-58, 2009

Since the initial observations of oral bacteria within dental plaque by van Leeuwenhoek using his primitive microscopes in 1680, an event that is generally recognized as the advent of oral microbiological investigation, oral microbiology has gone through phases of "reductionism" and "holism". From the small beginnings of the Miller and Black period, in which microbiologists followed Koch's postulates, took the reductionist approach to try to study the complex oral microbial community by analyzing individual species; to the modern era when oral researchers
\end{abstract}

embrace "holism" or "system thinking", adopt new concepts such as interspecies interaction, microbial community, biofilms, poly-microbial diseases, oral microbiological knowledge has burgeoned and our ability to identify the resident organisms in dental plaque and decipher the interactions between key components has rapidly increased, such knowledge has greatly changed our view of the oral microbial flora, provided invaluable insight into the etiology of dental and periodontal diseases, opened the door to new approaches and techniques for developing new therapeutic and preventive tools for combating oral polymicrobial diseases.

Keywords oral microbiology, biofilms, dental caries, oral pathogenesis

Document code: A CLC number: Q932 Received May 2, 2009

\section{Introduction}

Like many other biological sciences, the study of microbiology has gone through phases of "reductionism" and "holism". For a long time, microbiologists took the reductionist approach to study complex microbial communities by analyzing individual bacterial species. The strategy was to understand the whole by examining smaller components, and has been the hallmark of much of the industrial and scientific revolutions for the past 150 years. While reductionism has greatly advanced microbiology, it was recognized that assembly of smaller pieces cannot explain the whole! Modern microbiologists are learning "system thinking" and "holism." From global gene regulation to "metagenomics" to "biofilms", microbiology is entering an exciting new era with emphasis on revealing and decoding the interactions of different elements within a microbial community. The knowledge obtained from "system thinking" is changing our understanding of microbial physiology and our ability to diagnose/treat microbial infections, and will have great impact on oral microbiology as well.

Commonly known as "dental plaque", oral microbial communities is one of the most complex bacterial floras associated with human body. So far, more than 700 different bacterial species have been identified from human oral cavity, and the majority of them are associated with dental plaque (Paster et al., 2001; Aas et al., 2005; Paster et al., 2006). Extensive animal and clinical studies have indicated that the oral microbial flora is responsible for two major human oral diseases: dental caries (tooth decay) and periodontitis (gum disease) (Loe 
et al., 1965; Socransky, 1979; Dahlen, 1993; Marsh, 1994; Nishihara and Koseki, 2004). For a long time, oral microbiologists followed guideline of Koch's postulates, and used reductionism approach to try to identify the key pathogens responsible for oral microbial pathogenesis (Slots and Listgarten, 1988; Dzink et al., 1988; Haffajee and Socransky, 1994). However the limitation of reductionism forced microbiologists to embrace new concepts such as interspecies interaction, microbial community, biofilms, poly-microbial diseases, etc. These new research directions have revealed many new physiological functions critical for the pathogenesis, which result from interactions between different components within oral microbial flora, and might not be observed with individual organisms. The new "system thinking", empowered with the modern techniques for analyzing complex microbial community serves as a new foundation for studying oral microbial community, providing invaluable insight into the etiology of dental and periodontal diseases, developing new therapeutic and preventive tools for combating oral poly-microbial diseases.

\section{Oral microbiology at early stage}

Although minute and primordial, bacteria are incredibly versatile and diversified. Judging by their numbers and biomass, they are arguably the most successful living organisms on earth. They can tolerate environmental extremes and colonize almost every habitat on earth, including human oral cavity. However, due to their minuteness, their existence was not revealed until fairly recent times, around 1680, when van Leeuwenhoek (16321723) (Gest, 2004), a Dutch dry goods merchant, observed and described first microorganisms in the tartar from his teeth with his primitive microscope. In his notebook, he recorded 'I didn't clean my teeth for three days and then took the material that has lodged in small amounts on the gums above my front teeth...... I found a few living animalcules." The microbes sketched in his notebook are now known as some of the most abundant bacteria resided within oral cavity, including cocci, spirochetes, and fusiform bacteria. These fascinating observations at the birth of microbiology had already signaled the complexity of the oral micro- bial community.

Revealing the infectious nature of dental caries and periodontitis

Like many other sub-disciplines of microbiology, the early stage of development in oral microbiology was largely driven by medical needs. As two of the most prevalent human oral diseases, dental caries and periodontitis have always been the focus of oral microbiology research.

Dental caries is a human oral disease with a long history. Archaeological evidence shows that tooth decay is an ancient disease dating far back into prehistory (Suddick and Harris, 1990). Interestingly, studies by Moore and Corbett of the dentition of Britons in various periods demonstrated that, until about 1850 , caries occurred relatively infrequently; after 1850 , coinciding with the increasing availability of cane sugar and refined flour, there has been an explosive increase in dental caries lesions (Nikiforuk, 1985). Even from ancient time, long before the visual observation of microorganism, people had suspected the possible causative link between certain form of living organism - described as "tooth worm" in a Sumerian text about $5000 \mathrm{BC}$, and dental caries (Suddick and Harris, 1990). However, the revelation of the true identity of "tooth worms" had to wait for another 6000 years.

Miller was arguably one of the most important individuals who greatly advanced oral microbiology. As a practicing dentist with a thorough training in natural sciences, he spent his evenings and weekends at Koch's laboratory for the purpose of identifying the "germs" that were responsible for tooth decay. In his 1890 book titled "Microorganisms of the Human Mouth" (Miller, 1890), he proposed a "chemoparasitic" theory which suggested that, in susceptible hosts who frequently consumed fermentable carbohydrates, oral microorganisms would convert these carbohydrates into acid, which would result in the demineralization of teeth. Miller's chemoparasitic theory, together with the description of "gelatinous microbic plaques"now commonly known as "dental plaque", by Black and Williams (Black, 1898; Williams, 1898), provided the key elements for our modern concept of the etiology of dental caries. 
Due to the limited bacterial isolation and cultivation technique available in $19^{\text {th }}$ century, Miller was unable to identify the causative agent(s) of dental caries. In 1924, Clarke first isolated a bacterial species from human dental caries site, it was named Streptococcus mutans (S. mutans), and was shown to be capable of fermenting several sugars and producing a $\mathrm{pH}$ of 4.2 in glucose broth (Clarke, 1924). But unfortunately, Clarke was unable to demonstrate that this organism actually caused caries.

Since 1950, there has been an increasing interest in using experimental animal to better understand the nature and etiology of oral disease, including dental caries. Many relatively sophisticated animal models had been developed which has greatly facilitated oral microbiology studies (Jordan, 1971; Navia, 1977). In 1960, two important paper were published which were considered the cornerstone of dental caries research. In the first paper, using hamster as animal model, Keyes revealed the infectious and transmissible nature of dental caries (Keyes, 1960). Then in another elegant paper, Fitzgerald and Keyes successfully demonstrated caries induction in an animal harboring a "conventional" microflora, by a single type of streptococcus - the same bacterial species that had been isolated by Clarke more than 30 years ago (Fitzgerald and Keyes, 1960).

Other than dental caries, another major human oral disease is periodontitis, it is widely regarded as the second most common disease worldwide. The involvement of bacteria in the development of periodontal disease was suggested by the fact that administration of penicillin inhibited periodontitis in hamster (Mitchell and Johnson, 1956); while the infectious nature of this disease was substantiated by demonstration of its transmissibility (Keyes and Jordan, 1964). Early experimental animal study also identified several oral isolates, such as Actinomyces species, which could potentially play an important role in eliciting the disease (Howell et al., 1965).

\section{Establishing dental plaque as the cause of dental} caries and periodontitis

One of the early achievements in oral microbiology is to link dental plaques to dental and periodontal diseases. As mentioned earlier, dental plaque was one of the first substances van Leeuwenhoek examined under his microscope (Gest, 2004). His recording of the living microorganisms within the plaque gave the first hint to the complex nature of dental plaque in term of its diversified microbial inhabitants. Later on, both Erdi and Ficinus described the presence of microorganisms within the "membrane" on teeth (Suddick and Harris, 1990). However, the full implications of dental plaque were not realized until the publication of Black's 1898 paper, in which he referred dental plaque as "gelatinous microbic plaques", a gelatinlike substance that carried microorganisms (Black, 1898). Based on his clinical experience and experimentation, he believed that the cause of dental caries was due to the attack from acids generated by bacteria within these plaques. Black's work, together with Miller's chemoparasitic theory established the important role of dental plaque in the etiology of dental caries and has become one of the essential paradigms of oral biology. And the progress in dental plaque study has become a major indicator of the development of oral microbiology.

\section{Oral microbiology—Present}

\section{Genetic studies of bacterial isolates from dental plaque}

Since the establishment of microbes within dental plaque as the cause of dental and periodontal diseases, oral microbiologists followed the guideline of Koch's postulates and tried to isolate specific microorganisms that could be the causative agents and responsible for these disease. However, like in other microbiology fields, one of the challenges faced by early researchers in oral microbiology was the isolation and cultivation of "pure" bacterial culture. By the 1960s, anaerobic bacteria had been recognized as the predominant microbial component of the gastro-intestinal tract (including oral cavity) associated flora of human and mammals (Rosebury, 1962). During the process of bacterial cultivation, researchers realized that the majority of these anaerobic bacteria cannot be cultivated aerobically, or with the conventional anaerobic cultivation technique, such as, anaerobic culture 
tube introduced by Laidlaw (Laidlaw, 1915), the vacuum jar designed by Noguchi (Noguchi, 1911), and the anaerobic container-the "McIntosh bomb" developed by McIntosh and Fildes (McIntosh and Fildes, 1916). The introduction of anaerobic glove boxes - a primitive version of now widely used anaerobic chamber, by Socransky (Socransky et al., 1959) and Rosebury et al. (Rosebury and Reynolds, 1964) in the 1960s greatly facilitated the isolation and cultivation of anaerobes, particularly those obligate (strict) anaerobic microorganisms, from human oral cavity.

With improved anaerobic cultivation technique and availability of newly developed complex media for bacterial cultivation, pure cultures of more than 300 different oral bacteria species have been isolated from oral cavity in the past 40 years, including bacterial species harbored in both supragingival and sub-gingival dental plaque samples taken from healthy and diseased sites (Kolenbrander, 2000). The isolation and cultivation allowed detailed phenotypic and genetic study on those clinically important bacteria, such as Streptococcus, Actinobacillus, Actinomyces, Porphyromonas and Treponema species (Kolenbrander, 2000). The combination of classic genetic approaches, such as isolation and characterization of mutants, with molecular genetic techniques, including recombinant DNA methodology developed in the late 1970s and genetic mapping (Cohen et al., 1973), has been used to genetically manipulate and characterize those microorganisms important in dental caries and periodontal diseases. The genetic studies, together with the additional bio-informatic information obtained from whole genomic sequences of many oral bacteria (Zhulin, 2009) allow microbiologists to dissect the development and function of oral microbial community at the molecular level. Progress has been made in determining the molecular genetic basis of biofilm formation of oral isolates using data from in vitro studies on either single, dual species or multi-species systems. Studies have shown that in certain virulent organisms many different types of genes encoding a variety of functions are required for biofilm development and successful establishment within the dental plaque, including genes encoding general stress response pathways, quorum-sensing systems, twocomponent systems sensing environmental cues, and those encoding surface adhesions involved in cell-cell or cell-to-genes encoding surface interactions (Kolenbrander, 1988; Kolenbrander, 2000; Davey and Costerton, 2006; Kuramitsu et al., 2007).

\section{Getting a closer look at dental plaque}

The dental plaque has long been linked to the etiology of dental and periodontal diseases. The concept proposed by Black more than 100 years ago that caries was due wholly to attack from acids produced by bacteria within dental plaque has stimulated considerable scientific investigation on dental plaque. In the past few decades, there has been a tremendous amount of work and numerous exciting discoveries made during these investigations, ranging from dental plaque's microbial composition, structure to its formation process, from its physiology properties to different kinds and levels of bacterial interactions within these densely populated microbial community. The virtual explosion of our knowledge regarding dental plaque has had a profound impact on our understanding of the etiology of dental and periodontal diseases (Kolenbrander, 1988; Kolenbrander et al., 1999; Kolenbrander, 2000; Kolenbrander et al., 2002; Kolenbrander et al., 2005; Davey and Costerton, 2006; Kuramitsu et al., 2007).

Before the 1960s, although microorganisms within dental plaque were held responsible for the etiology of dental and periodontal disease, it was generally believed that diseases were the result of an increased mass of bacteria rather than qualitative differences in the composition of the microbiota. This was largely due to the lack of suitable cultivation techniques and the gaps in the knowledge of the taxonomy of the oral microbial flora. This conventional wisdom was challenged by Listgaten (Listgarten, 1976). By analyzing the dental plaque associated with periodontally healthy and diseased teeth using electron microscopy, he observed that distinct qualitative differences exist between supraand sub-gingival, healthy and disease associated plaque (Listgarten, 1976). These original microscopic observations were later confirmed by improved culture-dependent and non-culture dependent analysis.

In 1978, Costerton invented the word "biofilm", referring to the matrix-enclosed bacterial com- 
munity (Costerton et al., 1978). Studies have shown that bacteria within biofilms usually display different phenotypes compared with their counterparts. They are more resilient and more resistant to external insults. Within biofilm, there are extensive metabolites exchanges, signaling trafficking and different levels of interactions among different species (Costerton et al., 1987; Costerton et al., 1995; Costerton et al., 1999). The introduction of biofilm theory into oral microbiology field provided impetus for researchers to take a closer and thorough look at the dental plaque, the first biofilm described by van Leeuwenhoek.

Detailed analysis of a microbial community requires the full knowledge of its endogenous inhabitants. However, for a long time, our understanding of the microbial world has been hampered by the intrinsic limitation of the conventional culture-dependent methods. According to Staley and Konopka, fewer than $1 \%$ of the organisms are able to grow under laboratory conditions, suggesting that our views of the complexity and genetic diversity of microbial communities based on cultivation strategies are severely biased (Staley and Konopka, 1985). Fortunately, Woese and coworkers discovered three decades ago that the conservation as well as the variation within the sequences of 16S rRNA-encoding genes allows for the construction of evolutionary trees for bacteria to the species level (Saiki et al., 1985; Woese, 1987). This finding in combination with the development of PCR methods in 1985 (Saiki et al., 1985) opened the door for culture-independent analyses and classification of previously unknown members of many different microbial communities, including the resident flora of oral biofilms. The past two decades has witnessed a virtual explosion in the development of high-throughput tools for microbial community analysis. Some of these methods directly examine nucleic acids isolated from samples of microbial communities, such as microarrays (Small et al., 2001) and checkerboard DNA-DNA hybridization method (Socransky et al., 1994), while others are PCR based, such as denaturing gradient gel electrophoresis (DGGE) (Nakatsu, 2007) or temperature gradient gel electrophoresis (Yoshino et al., 1991), terminal restriction fragment length polymorphism (T-RFLP) (Liu et al., 1997; Thies, 2007), automated ribosomal intergenic spacer analysis (Cardinale et al., 2004), and denaturing high-performance liquid chromatography (DHPLC) (Domann et al., 2003). Most of these approaches were originally developed for analyzing environmental microbial communities and have been used to study human microbial ecology, including oral microbial analysis. These culture-independent techniques have revealed a whole new microbial world within dental plaque with great genetic diversity. Over 700 bacterial species (gram-positive, gram negative bacteria and archaea) have been identified form the human oral cavity, majority of them are associated with dental plaque, making the oral microbial community one of the most complex microbial floras in the human body (Aas et al., 2005; Paster et al., 2001; Aas et al., 2005; Paster et al., 2006). Based on our current knowledge, supragingival plaque is dominated by gram-positive bacteria, including Streptococcus sanguinis, S. mutans, Streptococcus mitis, Streptococcus salivarius, and lactobacilli, while the subgingival plaque is made up primarily by gram-negative anaerobic bacteria, such as Aggregatibacter (Actinobacillus) actinomycetemcomitans, Tannerella forsythia, Campylobacter spp., Capnocytophoga spp., Eikenella corrodens, Fusobacterium nucleatum, Porphyromonas gingivalis, Prevotella intermedia, and oral spirochetes such as Treponema denticola. In both cases, the microbial communities on teeth and gingival tissues can accumulate high concentrations of bacterial metabolites (e.g., fatty acid end products, ammonia, hydrogen peroxide, oxidants, and carbon dioxide) in their local environments, which influence the bacterial species within the microbial community, as well as the host (Carlsson, 1997).

To study the formation and architecture of dental plaque, several experimental designs have been developed. These include in vitro systems ranging from simple batch culture system (e.g., the Zürich Biofilm Model) (Guggenheim et al., 2004), constant depth film fermentor (CDFF) (Kinniment et al., 1996), saliva-conditioned flow cell (Foster and Kolenbrander, 2004), to artificial mouths (Pigman and Elliott, 1952; Russell and Coulter, 1975), as well as in situ device for the in vivo generation of intact dental plaque biofilms on natural tooth surface in human subjects (Wood et $a l ., 2000)$. Using imaging tools such as the scanning electron microscope (Listgarten, 1976; Theilade et 
al., 1976) and, more recently, the confocal laser scanning microscope (Netuschil et al., 1998; Wood et al., 2000), and coupled with variety of staining techniques, such as fluorescence in situ hybridization (FISH) (Foster and Kolenbrander, 2004; Wagner et al., 1994), oral microbiologist now realized that dental plaque are not unstructured, homogeneous deposits of cells, but complex, well organized communities of surface-associated cells enclosed in a polymer matrix containing open water channels and fluid-filled voids. In vitro and in vivo study on the formation and development of dental plaque revealed that during the formation process, some oral bacteria are early colonizers that express biochemical components allowing them to effectively adhere to targeted tissues (teeth or periodontal tissue). The later colonizers often contain components that enable them to adhere to the early colonizers, often bringing metabolic or other competitive advantages. Within an established dental plaque, specific bacterial species are often found located adjacent to each other or mixed together to form unique structures that often confer adherence or growth advantages. Previous comprehensive reviews by Kolenbrander et al. should be consulted for assessment of these important properties (Kolenbrander, 1988; Kolenbrander et al., 1999; Kolenbrander, 2000; Kolenbrander et al., 2005; Kolenbrander et al., 2006).

\section{Community based microbial pathogenesis}

The improved cultivation technique allows successful isolation and characterization of microbial species from dental plaque, which naturally prompted oral microbiologists to connect specific bacterial species to certain diseases, according to Koch's postulates. For example, as a result of such strategies, the acid-producing oral bacterium $S$. mutans present in supragingival plaque was selected for its positive correlation with dental caries, animal study also demonstrated its ability to induce dental caries. And this has become the base for "Specific plaque hypothesis" proposed by Loesche, which proposed that only a few specific species, such as $S$. mutans and Streptococcus sobrinus, are actively involved in the disease (Loe et al., 1965). However, additional scientific data have suggested that such a simple correlation may be an oversimplification.
Unlike many known medical pathogens that are "foreign invaders with specific virulence factors", the oral "pathogens" such as $S$. mutans are part of the normal flora (Aas et al., 2005). While they express certain pathogenic factors (such as acid production in this case), a dynamic balance of both synergistic and antagonistic interactions with its neighboring bacteria plays an essential role in determining whether these pathogenic factors cause damage or not (Kleinberg, 2002; Marsh, 2005). As proposed by Marsh in his "Ecological plaque hypothesis", in the case of complex biofilms, it is not merely the presence of a single organism in a complex community which determines the properties of a biofilm, but it is the interactions between the biofilm residents which is crucial (Marsh, 2005). As an example, in the presence of nearby baseproducing bacteria, $S$. mutans in dental plaque may not be as pathogenic to the host. Thus, for dental caries, it is now generally recognized that this disease results not solely because of the presence of S. mutans or any single organism in dental plaque. Rather, it is the result of the interaction of multiple acid-producing organisms such as $S$. mutans with other biofilm residents (Kleinberg, 2002; Marsh, 2005). Such a community- and microbial ecologybased pathogenic theory serves as a new concept for understanding the relationship between dental plaque and the host in health or disease, as well as suggesting new strategies for disease treatment and prevention.

Dental plaque is a microbial community with great structural complexity and genetic diversity. Its bacterial composition remains relatively stable despite regular exposure to minor environmental perturbations. This stability (microbial homeostasis) is due in part to a dynamic balance of both synergistic and antagonistic microbial interactions (Marsh, 1994; Kleinberg, 2002). This suggests that the residents in this community should display extensive interactions while forming biofilm structures, carrying out physiological functions, and inducing microbial pathogenesis. Extensive in vitro and animal studies have revealed a multitude of bacterial interspecies interaction as described in resent reviews. These interactions include (i) competition between bacteria for nutrients, (ii) synergistic interactions which may stimulate the growth or survival of one or more residents, (iii) produc- 
tion of an antagonist by one resident which inhibits the growth of another, (iv) neutralization of a virulence factor produced by one organism by another resident, and (v) interference in the growthdependent signaling mechanisms of one organism by another (Kolenbrander, 2000; Kolenbrander et al., 2005; Kolenbrander et al., 2006; Kuramitsu et al., 2007; Marsh, 1994; Marsh, 2005). In a microGaia community, these interactions could be envisaged as forms of "war and peace" among the bacterial residents of a biofilm.

Multispecies communities like dental plaque can produce polymicrobial infections in which microorganisms interact in a synergistic fashion, leading to pathogenesis. Periodontal diseases represent one of the best-documented polymicrobial infections. Porphyromonas gingivalis, Treponema denticola, and Tannerella forsythia are strongly implicated clinically as a pathogenic consortium in the etiology of adult periodontitis (Socransky et al., 1998; Feng and Weinberg, 2006). It is anticipated that a better understanding of the mechanisms involved in periodontitis may provide opportunities to more critically evaluate the role of different virulence factors involved in these mixed infections. This may provide useful general information for investigators in the development of novel diagnostic, preventive, and treatment strategies against polymicrobial infections

\section{Oral microbiology—Future}

\section{The future direction of oral dental plaque study- Metagenomics}

The aforementioned high-throughput tools for microbial community analysis are largely based on PCR amplification of 16S rRNA sequences from microbial communities, which are relatively short, often conserved but varied enough to differentiate bacteria at species level. Although these approaches can provide us with the microbial composition within the community, unless we have genomic or other research data on those identified species, it reveals very limited information regarding what functions they might carry out within the flora. The introduction and application of "metagenomics" approach has greatly enhanced and will continue to increase our ability to study microbial community, including dental plaque, in greater detail.

The term "metagenomics" was first invented by Handelsman (Handelsman et al., 1998), and it is defined as "the application of modern genomics techniques to the study of communities of microbial organisms directly in their natural environments, bypassing the need for isolation and lab cultivation of individual species". The advances in refinements of DNA amplification, bioinformatics, and enhanced computational power for analyzing DNA sequences have enabled the adaptation of shotgun sequencing, such as chip-based pyrosequencing, to metagenomic samples (Breitbart et al., 2002; Edwards et al., 2006). The approach randomly shears DNA, sequences many short sequences, and reconstructs them into a consensus sequence (Breitbart et al., 2002).

By performing metabolic function analyses on genes identified via metagenomic approach, researchers are able to retrieve information both on which organisms are present and more importantly, what functions or metabolic processes are possible in that particular community (Gill et al., 2006). Using comparative genetic studies coupled with expression experiments such as microarray and proteomics, microbiologist will be able to piece together a metabolic network that goes beyond species boundaries, and gain valuable insight into the metabolism within the community. Recently, comparative metagenomic study has been initiated to try to compare the microbial community within dental plaque associated with healthy and diseased sites. The results should become available in the next few years. It is anticipated that such comparison will assist in identifying potential pathogenic organisms which may not have been detected using currently available technologies (Kumar et al., 2003).

\section{Evidence based dental caries diagnosis}

Although the infectious nature of dental caries has been proved for more than 100 years, instead of treating it as infectious disease, traditional dentistry still holds sway and focuses on treating the symptom (repair the damaged tooth) via surgical approaches. The recent advanced knowledge we have gained about caries pathogenesis allows us to 
understand that a comprehensive analysis of dental caries should be more than detecting tooth demineralization sites and repairing damaged teeth with surgical approaches. Instead, it should include the detection of cariogenic bacteria and plaque acidogenicity, followed by a comprehensive treatment of dental caries that includes the elimination of cariogenic bacteria, the reduction of plaque acidogenicity and the enhancement of tooth reminerlization (Tsang et al., 2006). The combination of accurate detection of oral bacteria and in situ monitoring of plaque $\mathrm{pH}-$ such as the polyaniline-based planer $\mathrm{pH}$ sensor developed by scientists at Jet Propulsion Laboratory, and combined NMR confocal microscopy from Pacific Northwest Laboratory which can monitor $\mathrm{pH}$ gradient within dental plaque with high sensitivity and in real time (Majors et al., 2005), is opening a new chapter for cariology. Early detection and quantification of cariogenic bacteria in plaque or saliva samples can help clinicians take preventive measures to stop caries development, much like early detection of cancer markers can be detected before overt/ detectable cancerous lesions develop. New antibody or nucleotide based bacterial detection techniques have been developed for the detection of cariogenic bacteria in chairside or laboratory settings (Shi et al., 1998). In conjunction with nanotechnology development, there tests can be further developed into different forms of nano-chips for detection of multiple pathogens in the clinical settings (Li et al., 2005).

\section{New approaches for controlling dental and perio-} dontal diseases

Current preventive dental therapy is primarily focused on removing dental plaque. Since it is now known that dental plaque is made of large numbers of commensal bacteria together with a limited number of pathogens (Aas et al., 2005; Paster et al., 2006), such an approach may not be effective since the "remove all or kill all" approach creates open, non-competitive surfaces for pathogens to repopulate the oral cavity. With our new understanding of the oral microbial community interactions, and the wide recognition of microbial ecology based theory on dental and periodontal diseases, there is now interest in approaches that selectively inhibit oral pathogens or modulate the microbial composition of dental plaque to control community based microbial pathogenesis. Among them, the probiotic approach has been a popular methods used to affect microbial communities.

The term "probiotics" refers to "live microorganisms, which when administered in adequate amount, confer a health benefit on the host" (Guarner et al., 2005). Recently, more evidence suggested that probiotic therapy might be applied to the maintenance of oral health (Caglar et al., 2006; Meurman and Stamatova, 2007). Using randomized controlled trials, Meurman et al. demonstrated that long-term consumption of milk containing the probiotic Lactobacillus rhamuosus GG strain reduced initial caries in kindergarten children (Nase et al., 2001). While Hillman and colleagues introduced a non-acid poducing $S$. mutans strain that produce a bacteriocin active against other $S$. mutans strains into the oral cavity to replace the naturally occurring cariogenic strains. Both in vitro and animal model asscessment suggested its potential in reducing $S$. mutans colonization. This approach is awaiting evaluation for its efficacy in humans (Hillman, 2002).

Since the beneficial effects of probiotic therapy are mainly achieved through modulating existing microbial flora associated with the host, thus obtaining a balanced and healthy microbe-host relationship, instead of using live organisms, microbiologists are now developing novel techniques and products that do not involve live bacteria, yet generate targeted effects against pathogenic factors or organisms, thus, achieving similar probiotic effects (He et al., 2009). One good example is the targeted antimicrobial therapy via a novel specifically targeted-anti-microbial peptides (STAMPs) technology (Eckert et al., 2006). A "STAMP" is a fusion peptide with two moieties: a killing moiet made of a non-specific anti-microbial peptide and a targeting moiety containing a species-specific binding peptide. The targeting moiety provides specific binding to a selected pathogen and facilitates the targeted delivery of an attached antimicrobial peptide. In one of their published papers, Eckert et al. explored a pheromone produced by $S$. mutans, namely competence-stimulating peptide (CSP), as a STAMP targeting domain to mediate S. mutans-specific delivery of and killing domain. 
They discovered that such STAMPs were potent against $S$. mutans grown in liquid as well as in biofilm states (Eckert et al., 2006). The STAMPs were capable of eliminating $S$. mutans from multispecies biofilms without affecting closely related non-cariogenic oral streptococci, indicating the potential of these molecules to be developed into "probiotic" antimicrobials that may selectively eliminate pathogens while preserving the protective benefits of the normal flora. This proof-of-principle demonstration using $S$. mutans suggests that it may be possible to develop other STAMPs which are specifically targeted to other pathogens, including periodontal pathogens within oral cavity.

\section{Conclusions}

Since the initial observations of bacteria within dental plaque by van Leeuwenhoek using his primitive microscopes in 1680 , an event that is generally recognized as the advent of oral microbiological investigation, our ability to identify the resident organisms in dental plaque and decipher the interactions between key components has rapidly increased, particularly during the past decade. Continued expansion of such information in the future will have a great impact on oral microbiology and dentistry as well. We envision that in the future, empowered with the detailed knowledge of the microbial community ecology within dental plaque, the invention and application of new diagnostic tools, dentistry will be an evidence-based dental practice emphasizing the triple-pronged approach of early detection, effective and sustainable treatment, and prevention. Specifically, pathogen-based early detection will become routine, which will allow instantaneous chairside quantification of cariogenic bacteria in plaque or saliva samples. This clinical adjunct will help the clinician reinforce the concept of dental caries as an infectious process and will facilitate immediate, evidence-based treatment decisions.

The progress in oral microbiology will continue to provide in-depth understanding of the ecological tug-of-war between the indigenous microbial flora and the cariogenic, periodontal pathogens. And it will become a gateway leading to more specific and practive therapeutic approaches in combating dental and periodontal diseases.

\section{References}

Aas JA, Paster BJ, Stokes LN, Olsen I, Dewhirst FE (2005). Defining the Normal Bacterial Flora of the Oral Cavity. J Clin Microbiol, 43(11): 5721-5732.

Black GV (1898). Dr. Blacks conclusions reviewed again. Dent Cosmos, 40: 440.

Breitbart M, Salamon P, Andresen B, Mahaffy JM, Segall AM, Mead D, et al. (2002). Genomic analysis of uncultured marine viral communities. Proc Natl Acad Sci USA, 99(22): 14250-14255.

Caglar E, Cilder SK, Ergeneli S, Sandalli N, Twetman S (2006). Salivary mutans streptococci and lactobacilli levels after ingestion of the probiotic bacterium lactobacillus reuteri ATCC 55739 by straws or tablets. Acta Odonto Scand, 64(5): 314-318.

Cardinale M, Brusetti L, Quatrini P, Borin S, Puglia AM, Rizzi A, et al. (2004). Comparison of different primer sets for use in automated ribosomal intergenic spacer analysis of complex bacterial communities. Appl Environ Microbiol, 70(10): 6147-6156.

Carlsson J (1997). Bacterial metabolism in dental biofilms. Adv Dent Res, 11(1): 75-80.

Clarke JK (1924). On the bacterial factor in the etiology of dental caries. Br J Exp Pathol, 5: 141-147.

Cohen SN, Chang AC, Boyer HW, Helling RB (1973). Construction of biologically functional bacterial plasmids in vitro. Proc Natl Acad Sci USA, 70(11): 32403244.

Costerton JW, Cheng KJ, Geesey GG, Ladd TI, Nickel JC, Dasgupta M (1987). Bacterial biofilms in nature and disease. Annu Rev Microbiol, 41: 435-464.

Costerton JW, Geesey GG, Cheng GK (1978). How bacteria stick. Sci Am, 238(1): 86-95.

Costerton JW, Lewandowski Z, Caldwell DE, Korber DR, Lappin-Scott HM (1995). Microbial biofilms. Annu Rev Microbiol, 49: 711-745.

Costerton JW, Stewart PS, Greenberg EP (1999). Bacterial biofilms: a common cause of persistent infections. Science, 284 (5418): 1318-1322.

Dahlén G (1993). Role of suspected periodontopathogens in microbiological monitoring of periodontitis. $A d v$ Dent Res, 7(2): 163-174.

Davey MA, Costerton JW (2006). Molecular genetics analyses of biofilm formation in oral isolates. Periodontology 2000, 42: 13-26.

Domann E, Hong G, Imirzalioglu C, Turschner S, Kühle J, 
Watzel C, et al. (2003). Culture-independent identification of pathogenic bacteria and polymicrobial infections in the genitourinary tract of renal transplant recipients. J Clin Microbiol, 41(12): 5500-5510.

Dzink JL, Socransky SS, Haffajee AD (1988). The predominant cultivable microbiota of active and inactive lesions of destructive periodontal diseases. J Clin Periodontol, 15(5): 316-323.

Eckert R, He J, Yarbrough DK, Qi F, Anderson MH, Shi W (2006). Targeted killing of Streptococcus mutans by a pheromone-guided "Smart" antimicrobial peptide. Antimicrob Agents Chemother, 50(11): 3651-3657.

Edwards RA, Rodriguez-Brito B, Wegley L, Haynes M, Breitbart M, Peterson DM, et al. (2006). Using pyrosequencing to shed light on deep mine microbial ecology. BMC Genomics, 7: 57.

Feng Z, Weinberg A (2006). Role of bacteria in health and disease of periodontal tissues. Periodontology 2000, 40: $50-76$.

Fitzgerald RJ, Keyes PH (1960). Demonstration of the etiologic role of streptococci in experimental caries in the hamster. J Am Dent Assoc, 61: 9-19.

Foster JS, Kolenbrander PE (2004). Development of a multispecies oral bacterial community in a salivaconditioned flow cell. Appl Environ Microbiol, 70(7): $4340-4348$.

Gest H (2004). The discovery of microorganisms by Robert Hooke and Antoni van Leeuwenhoek, Fellows of The Royal Society. Notes Rec R Soc Lond, 58(2): 187-201.

Gill SR, Pop M, Deboy RT, Eckburg PB, Turnbaugh PJ, Samuel BS, et al. (2006). Metagenomic analysis of the human distal gut microbiome. Science, 312(5778): 1355-1359.

Guarner F, Perdigon G, Corthier G, Salminen S, Koletzko B, Morelli L (2005). Should yoghurt cultures be considered probiotic? Br J Nutr, 93(6): 783-786.

Guggenheim B, Guggenheim M, Gmür R, Giertsen E, Thurnheer T (2004). Application of the Zurich Biofilm Model to problems of cariology. Caries Res, 38(3): 212-222.

Haffajee AD, Socransky SS (1994). Microbial etiological agents of destructive periodontal diseases. Periodontology 2000, 5: 78-111.

Handelsman J, Rondon MR, Brady SF, Clardy J, Goodman RM (1998). Molecular biological access to the chemistry of unknown soil microbes: a new frontier for natural products. Chem Biol, 5 (10): R245-R249.

He X, Lux R, Kuramitsu HK, Maxwell HA, Shi W (2009). Achieving probiotic effects via modulating oral microbial ecology. Adv Dent Res, 21.

Hillman JD (2002). Genetically modified Streptococcus mutans for prevention of dental caries. Antoine van Leewenhoek, 82 (1-4): 361-366.

Howell AJ, Jordan HV, Georg LK, Pine L (1965). Odontomyces viscosus, gen. nov., spec. nov, a filamentous microorganism isolated from periodontal plaque in hamsters. Sabouraudia, 4(2): 65-68.

Jordan HV (1971). Rodent model systems in periodontal disease research. $J$ Dent Res, 50(2): 236-242.

Keyes PH (1960). Infections and transmissible nature of experimental dental caries. Arch Oral Biol, 1: 304320.

Keyes PH, Jordan HV (1964). Periodontal lesions in the Syrian hamster. III. Findings related to an infectious and transmissible component. Arch Oral Biol, 9: $377-400$.

Kinniment SL, Wimpenny JW, Adams D, Marsh PD (1996). Development of a steadystate oral microbial biofilm community using the constant-depth film fermenter. Microbiology, 142 ( Pt 3): 631-638.

Kleinberg I (2002). A mixed-bacterial ecological approach to understanding the role of oral bacteria in dental caries causation: an alternate to Streptococcus mutans and the specific-plaque hypothesis. Crit Rev Oral Biol Med, 13(2): 108-125.

Kolenbrander PE (1988). Intergeneric coaggregation among human oral baceria and ecology of dental plaque. Annu Rev Microbiol, 42: 627-656.

Kolenbrander PE (2000). Oral microbial communities: biofilms, interactions, and genetic systems. Annu Rev Microbiol, 54: 413-437.

Kolenbrander PE, Andersen RN, Blehert DS, Egland PG, Foster JS, Palmer RJJ (2002). Communication among oral bacteria. Microbiol Mol Biol Rev, 66(3): 486-505.

Kolenbrander PE, Andersen RN, Kazmerzak K, Wu R, Palmer RJJ (1999). Spatial organization of oral bacteria in biofilms. Methods Enzymol, 310: 322-332.

Kolenbrander PE, Egland PG, Diaz PI, Palmer JRJ (2005). Genome-genome interactions: bacterial communities in initial dental plaque. Trends Microbiol. 13(1): 1115.

Kolenbrander PE, Palmer RJJ, Rickard AH, Jakubovics NS, Chalmers NI, Diaz PI (2006). Bacterial interactions and successions during plaque development. Periodontology 2000, 42:47-79.

Kumar PS, Griffen AL, Barton JA, Paster BJ, Moeschberger ML, Leys EJ (2003). New bacterial species associated with chronic periodontitis. J Dent Res, 
82(5): 338-344.

Kuramitsu HK, He X, Lux R, Anderson MH, Shi W (2007). Interspecies interactions within oral microbial communities. Microbiol Molecul Biol Rev, 71(4): 653-670.

Laidlaw PP (1915). Some simple anaerobic methods. Brit Med J, 1: 497-498.

Li Y, Denny P, Ho CM, Montemagno C, Shi W, Qi F (2005). The Oral Fluid MEMS/NEMS Chip (OFMNC): diagnostic and translational applications. Adv Dent Res, 18(1): 3-5.

Listgarten MA (1976). Structure of the microbial flora associated with periodontal health and disease in man: a light and electron microscopic study. J Periodontol, 47(1): 1-18.

Liu W, Marsh T, Cheng H, Forney L (1997). Characterization of microbial diversity by determining terminal restriction fragment length polymorphisms of genes encoding 16S rRNA. Appl Environ Microbiol, 63(11): 4516-4522.

Loe H, Theilade E, Jensen S (1965). Experimental gingivitis in man. J Periodontol, 36: 177-187.

Loesche WJ (1992). The specific plaque hypothesis and the antimicrobial treatment of periodontal disease. Dent Update, 19(2): 68-74.

Majors PD, McLean JS, Pinchuk GE, Fredrickson JK, Gorby YA, Minard KR (2005). NMR methods for in situ biofilm metabolism studies. J Microbiol Methods, 62(3): 337-344.

Marsh PD (2005). Dental plaque: biological significance of a biofilm and community life-style. J Clin Periodontol, 32(Suppl 6): 7-15.

Marsh PD (1994). Microbial ecology of dental plaque and its significance in health and disease. Adv Dent Res, 8(2): 263-271.

McIntosh J, Fildes P (1916). A new apparatus for the isolation and cultivation of anaerobic micro-organisms. Lancet, 1:768-770.

Meurman JH, Stamatova I (2007). Probiotics: contributions to oral health. Oral Dis, 13(5): 443-451.

Miller WD (1890). The micro-organisms of the human mouth. Biel: Graphische Anstalt Schuler AG.

Mitchell DF, Johnson MJ (1956). The nature of the gingival plaque in the hamster-production, prevention, and removal. J Dent Res, 35(4): 651-655.

Nakatsu CH (2007). Soil microbial community analysis using denaturing gradient gel electrophoresis. Soil Sci Soc Am J, 71(2): 562-571.

Nase L, Hatakka K, Savilahti E, Saxelin M, Ponka A, Poussa T, et al. (2001). Effect of long-term consumption of a probiotic bacterium, Lactobacillus rhamnosus GG, in milk on dental caries and caries risk in children. Caries Res, 35(6): 412-420.

Navia JA (1977). Animal models in dental research. Birmingham: University of Alabama Press.

Netuschil L, Reich E, Unteregger G, Sculean A, Brecx M (1998). A pilot study of confocal laser scanning microscopy for the assessment of undisturbed dental plaque vitality and topography. Arch Oral Biol, 43(4): 277-285.

Nikiforuk G (1985). Understanding dental caries. Vol. 1. Basel: Karger, pp.60.

Nishihara T, Koseki T (2004). Microbial etiology of periodontitis. Periodontology 2000, 36: 14-26.

Noguchi H (1911). A method for the pure cultivation of pathogenic Treponema pallidum. J Exp Med, 14(2): 99-112.

Paster BJ, Boches SK, Galvin JL, Ericson RE, Lau CN, Levanos VA, et al. (2001). Bacterial diversity in human subgingival plaque. J Bacteriol, 183(12): 3770-3783.

Paster BJ, Olsen I, Aas JA, Dewhirst FE (2006). The breadth of bacteria diversity in the human periodontal pocket and other oral sites. Periodontology 2000, 42: $80-87$.

Pigman W, Elliott HC (1952). An artificial mouth for caries research. J Dent Res, 31(5): 627-633.

Rosebury T (1962). Microorganisms indigenous to man. New York: McGraw-Hill Book Co., Inc.

Rosebury T, Reynolds JB (1964). Continuous anaerobiosis for cultivation of spirochetes. Proc Soc Exptl Biol Med, 117: 813-815.

Russell C, Coulter WA (1975). Continuous monitoring of $\mathrm{pH}$ and Eh in bacterial plaque grown on a tooth in an artificial mouth. Appl Microbiol, 29(2): 141-144.

Saiki R, Scharf S, Faloona F, Mullis K, Horn G, Erlich H, Arnheim N (1985). Enzymatic amplification of betaglobin genomic sequences and restriction site analysis for diagnosis of sickle cell anemia. Science, 230(4732): $1350-1354$.

Shi W, Jewett A, Hume WR (1998). Rapid and quantitative detection of Streptococcus mutans with species-specific monoclonal antibodies. Hybridoma, 17(4): 365-371.

Slots J, Listgarten MA (1988). Bacteroides gingivalis, Bacteroides intermedius and Actinobacillus actinomycetemcomitans in human periodontal diseases. $J$ Clin Periodontol, 15(2): 85-93.

Small J, Call DR, Brockman FJ, Straub TM, Chandler DP (2001). Direct detection of 16S rRNA in soil extracts by using oligonucleotide microarrays. Appl Environ 
Microbiol, 67(10): 4708-4716.

Socransky SS (1979). Criteria for the infectious agents in dental caries and periodontal disease. J Clin Periodontol, 6(7): 16-21.

Socransky SS, Haffajee AD, Cugini MA, Smith C, Kent RL (1998). Microbial complexes in subgingival plaque. J Clin Periodontol, 25(2): 134-144.

Socransky SS, MacDonald JB, Sawyer S (1959). The cultivation of Treponema microdentium as surface colonies. Arch Oral Biol, 1: 171-172.

Socransky SS, Smith C, Martin L, Paster BJ, Dewhirst FE, Levin AE (1994). "Checkerboard" DNA-DNA hybridization. BioTechniques, 17(4): 788-792.

Staley JT, Konopka A (1985). Measurement of in situ activities of nonphotosynthetic microorganisms in aquatic and terrestrial habitats. Annu Rev Microbiol, 39: 321-346.

Suddick RP, Harris NO (1990). Historical perspectives of oral biology: a series. Crit Rev Oral Biol Med, 1(2): $135-151$.

Theilade J, Fejerskov O, Horsted M (1976). A transmission electron microscopic study of 7-day old bacterial plaque in human tooth fissures. Arch Oral Biol, 21(10): $587-598$

Thies JE (2007). Soil microbial community analysis using terminal restriction fragment length polymorphisms. Soil Sci Soc Am J, 71(2): 579-591.

Tsang P, Qi F, Shi W (2006). Medical approach to dental caries: fight the disease, not the lesion. Pediatr Dent, 28(2): 188-191.

Wagner M, Assmus B, Hartmann A, Hutzler P, Amann R (1994). In situ analysis of microbial consortia in activated sludge using fluorescently labelled, rRNA-targeted oligonucleotide probes and confocal scanning laser microscopy. J Microsc, 176(Pt 3): 181-187.

Williams JL (1898). On structural changes in human enamel; with special reference to clinical observations on hard and soft enamel. Dental Cosmos, 40: 505.

Woese CR (1987). Bacterial evolution. Microbiol Rev, 51(2): 221-271.

Wood SR, Kirkham J, Marsh PD, Shore RC, Naltress B, Robinson C (2000). Architecture of intact natural human plaque biofilms studied by confocal laser scanning microscopy. J Dent Res, 79(1): 21-27.

Yoshino K, Nishigaki K, Husimi Y (1991). Temperature sweep gel electrophoresis: a simple method to detect point mutations. Nucleic Acids Res, 19(11): 3153.

Zhulin IB (2009). It is computation time for bacteriology! $J$ Bacteriol, 191(1): 20-22.

*Corresponding author: Wen-yuan Shi

Address: the University of California School of Dentistry, Los Angeles, California 90095, USA

Tel: $3108258356 \quad$ Fax: $3107947109 \quad$ E-mail:wenyuan@ucla.edu 